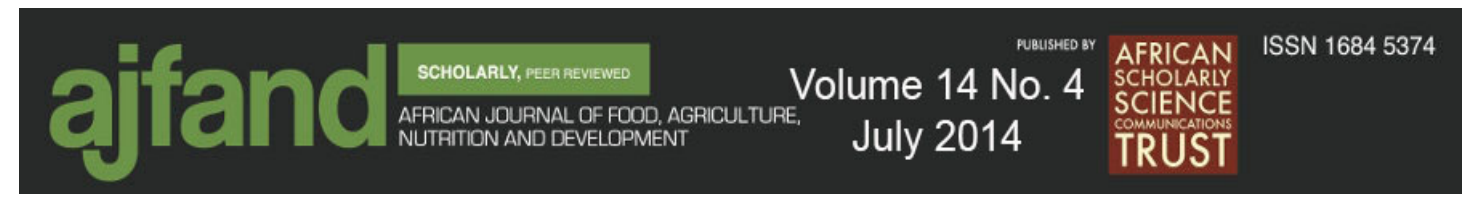

\title{
COMPLEMENTARY FEEDING PRACTICES \\ IN WAKISO DISTRICT OF UGANDA
}

\author{
Ssemukasa EL ${ }^{* 1}$ and J Kearney ${ }^{2}$
}

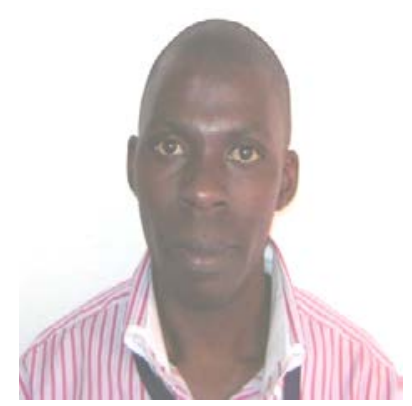

Edward Ssemukasa

*Corresponding author’s email: Isedward81@yahoo.com

${ }^{1}$ Present address: Lecturer in Engineering of Biological Materials, Department of Agro-Processing Engineering, Busitema University, P.O. Box 236, Tororo, Uganda

${ }^{2}$ John Kearney, Lecturer in Nutrition and Epidemiology, Department of Biological Sciences, Department of Biological Sciences, Dublin Institute of Technology, Dublin, Ireland. 


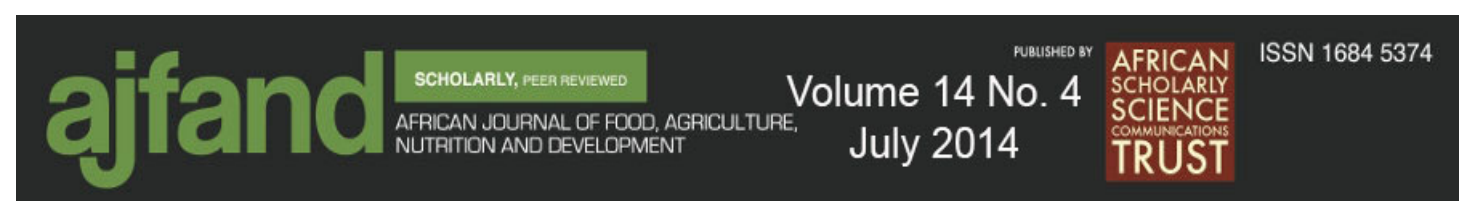

\section{ABSTRACT}

The first 2 years of life provide a critical window of opportunity for ensuring children's appropriate growth and development through optimal feeding. The objective of this study was to evaluate the prevalence of weaning practices in Wakiso district. Wakiso is a district in central Uganda that encircles Kampala, Uganda's capital city. The district is named after the town of Wakiso, where the district headquarters are located. A descriptive survey to evaluate infant weaning practices was conducted at Nsanji Health Centre III, Wakiso district from July through October 2011. Mothers with no established HIV/AIDS positive status aged 15 years and above, with last born-child aged 1-23 months, willing to provide data on the infant's feeding practices and regular attendants for infant vaccination schedules on Tuesday at the same facility were targeted. The motherinfant pairs were systematically selected for participation in the study based on the number of mothers together with their infants present every Tuesday morning of each week, for vaccinations at the health centre since the health centre had no database for the breastfeeding mothers. A structured questionnaire focusing on breastfeeding practices, complementary feeding practices, mineral supplementation and fluids administration, child's state of wellbeing in first year of life, mothers' age and parity was administered. A total of 204 mother-infant pairs were analysed. Overall, 94\% of 204 infants who participated in the study had not been exclusively breastfed for 6 months. Only one of the 124 infants between 0- 6 months of age and 5.9\% of the 80 infants over 6 months of age were still exclusively breastfeeding at the time of the survey. Complementary foods were introduced earlier than recommended with $22 \%$ of the mothers introducing solid foods before 1 month, $14 \%$ at $1-3$ months and $6 \%$ at $4-6$ months. Family members ( $p=0.001$ ) were a significant source of information on when to start feeding infants solid foods. In conclusion, the low exclusive breastfeeding rates, the early introduction of complementary foods and cow milk and the late introduction of red meat into the infant diets may well be responsible for the high level of infant infections recorded in the first year of infancy. Therefore, a nutritional education intervention, promoting exclusive breastfeeding, highlighting the health and food safety risks associated with the early introduction of cow milk into the infant diets could help reduce the high levels of infant infections and mortality in Uganda.

Key words: Exclusive breastfeeding, Complementary feeding practices 


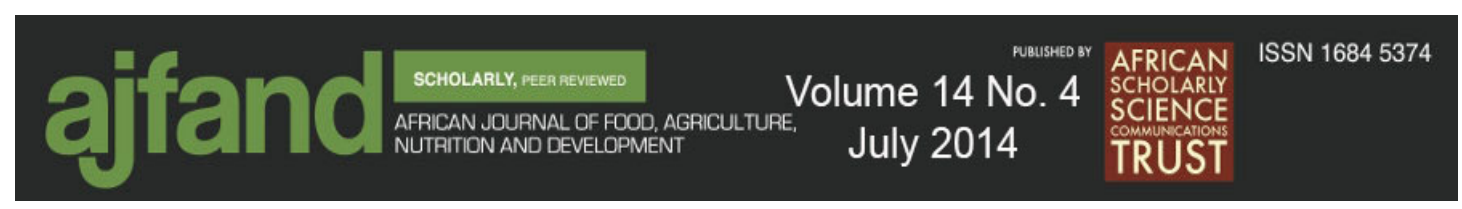

\section{INTRODUCTION}

Infants should be exclusively breastfed for 6 months to achieve optimal growth and development. They should be given adequate nutritional benefits and safe complementary feeding from the age of 6 months with continued breastfeeding up to 2 years of age or beyond [1]. Complementary foods should also meet the infant's daily energy requirements. An estimated 1.3 million lives are lost annually due to inadequate exclusive breastfeeding with an additional 600,000 from lack of continuation of breastfeeding with proper complementary feeding [1].

Complementary foods are introduced fairly early in a child's life with many infants and young children in sub-Saharan Africa subsisting on gruel and porridge prepared from staples, accompanied with vegetables and legumes, and only occasionally, animal foods [2]. In eastern Kenya, by age 3 months, $90 \%$ of infants are already receiving supplemental feedings of cow milk and maize or millet gruels with some evidence that introducing cereal gruel before age 4 months is associated with malnutrition [3]. Malnutrition undermines economic growth through direct loss of productivity resulting from weak physical status, indirect loss from fragile cognitive development, increased child morbidity and mortality and loss incurred due to increased health care costs in treating infections [4]. Inappropriate feeding practices are also responsible for growth faltering in infants. Moreover, a study by Shrimpton et al. [5] on the growth of individual children, showed that most of the infants malnourished at ages 3 to 5 years, present anthropometric deficits at the end of the first year of life.

In Uganda, more than 38\% of children below 5 years are stunted [6]. In eastern Uganda, 40\% of children below 5 years suffer from iron deficiency anaemia [7]. Vitamin A deficiency was found to be a public health problem in the country according to WHO criteria with Xerophthalmia diagnosed in $5.38 \%$ of the children, 2.52\% had night blindness, 1.74\% had corneal scars, $1.04 \%$ had Bitot's spots, and $0.26 \%$ had corneal xerosis [8]. Uganda has an infant mortality rate of 75/1,000 live births and an under 5 mortality rate of 137/1,000 [9]. However, a downward trend in infant and child mortality rates has been reported in the last 15 years. The mortality rate of children below 5 years between 2001 and 2006 dropped from 157 to 137deaths/1,000 live births and to 130 in 2009 [10]. Malaria constitutes $25 \%$ of the child death, $19 \%$ are due to respiratory infections and $17 \%$ due to diarrhoea [10].

Breastfeeding remains a culturally accepted practice in Uganda with up to $99 \%$ of women initiating breastfeeding [11]. However, exclusive breastfeeding rates remain low in the country [11]. About 62\% of all children below 6 months of age are exclusively breastfed as compared to $74 \%$ of those aged below 4 months [12]. However, little information is available on timing of initiation and type of complementary foods fed to infants in Uganda. This makes it hard for mothers to choose nutritious solid foods for their infants hence childhood malnutrition, 


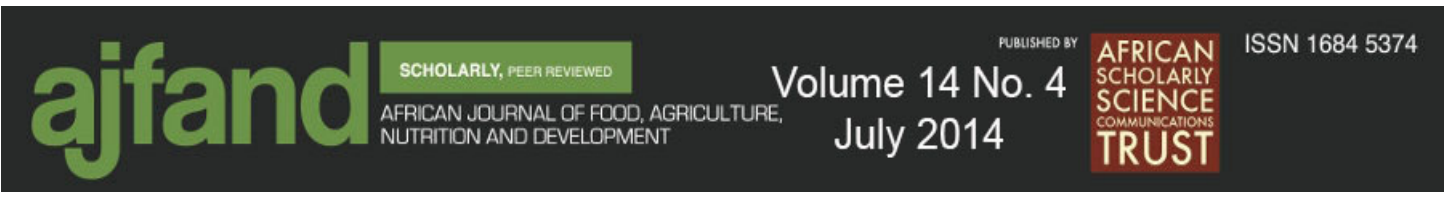

growth faltering and mortality. The information on complementary feeding practices is essential since it will act as reference information to health policy makers in Uganda. The aim of this study is to establish the prevalence of exclusive breastfeeding, timing of initiation and type of complementary foods fed to 1-23 month old infants in Wakiso district, Uganda.

\section{METHODS}

\section{Study area}

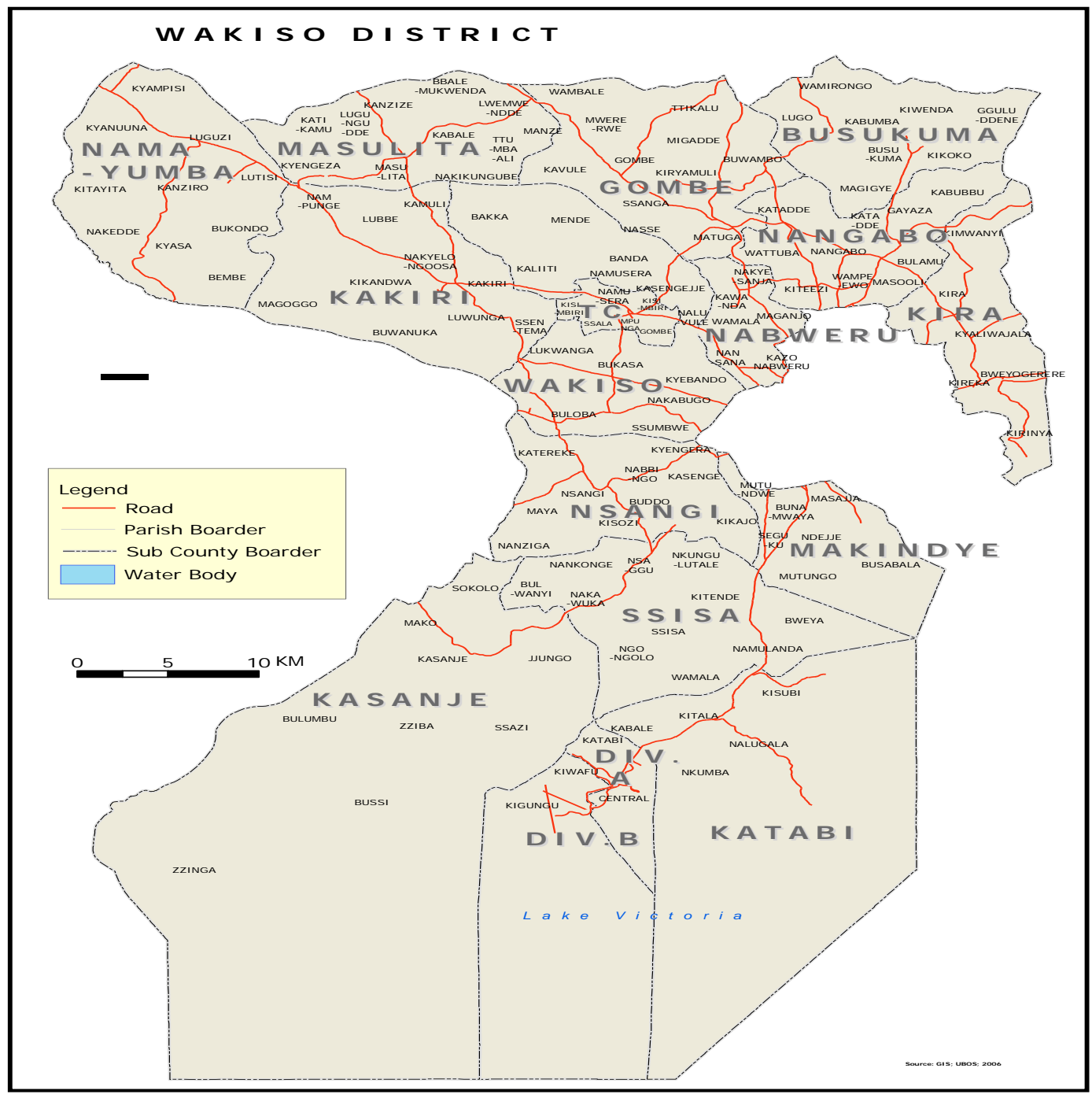

Figure 1: Map of Wakiso district

A descriptive survey of the infant feeding practices was undertaken at Nsanji Health Centre III, Wakiso district, Uganda. Wakiso is a district in central Uganda that encircles Kampala, Uganda's capital city. The district is named after the town of Wakiso, where the district headquarters are located. Wakiso's projected 


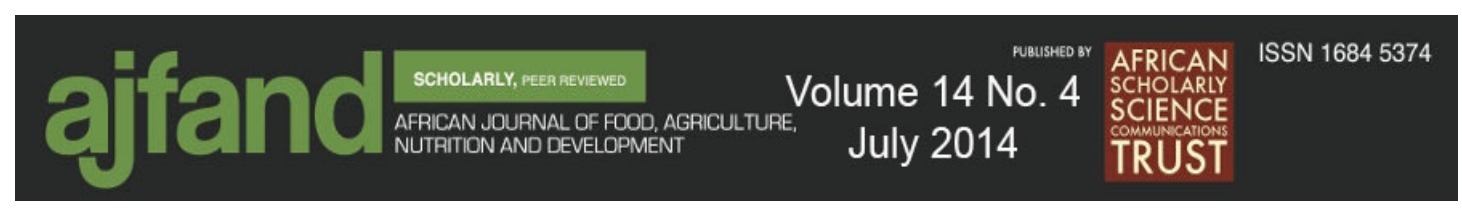

population (which is a mixture of urban, suburban and rural Ugandans with significant poverty) by 2012 was 1,371,600 people of whom 713,400 are females [13]. Ninety two percent of the district's population live in the rural areas [13].

\section{Study Population}

The study population comprised of mothers aged 15 years and above, who consented to provide information about their infant feeding practices and state of well-being in the first year of life and having children aged 1-23 months. The mothers, who were following-up the immunisation schedules for the children, must also not have tested positive for HIV/AIDS. The age category of infants and children was chosen on the basis of recommendations of the maximum total breastfeeding period of 24 months and beyond [1]. Also, it was because the first 2 years of life provide a critical window of opportunity for ensuring children's appropriate growth and development through optimal feeding [4]. The mothers were selected as the main respondents since they are the first in line in regard to infant feeding and are normally the ones who take children for vaccination.

\section{Sampling}

The Nsanji Health Centre III was chosen based on the recommendations and approval of the Wakiso District Health Officer. The management and staff of the health centre, who had firstly been informed of the aim of the study, explained the project aim to the mothers on arrival for immunization on the Tuesday morning of each week (Tuesday is the day that is designated for vaccinations at various health centres in Uganda). The mothers and children (whose ages were read from the immunization cards) who met the selection criteria were identified and targeted for inclusion in the study. A total of 273 mothers were targeted for inclusion in the study and verbally asked to participate and those who consented constituted the study sampled. Recruitment depended entirely on the number of mothers who met the selection criteria. A total of 250 mother-infant pairs were sampled and the immunization cards of their children dated with a red pen in the top-right hand corner to avoid multiple participations. The completed interview rate of $75 \%$ $(n=204)$ was used for the analyses of this study.

\section{Study instrument}

The instrument utilised in this study consisted of a structured questionnaire that included a total of 48 closed-ended questions. The questionnaire had 3 parts - one section on early infant feeding practices, another on weaning and the introduction of solid foods and a third on sample characteristics including infant health. In addition, the child's national growth and monitoring chart (immunization card) was used to establish the child's date of birth and mothers age. The mothers were asked not to fill in the infants' name as a confidentiality measure that was agreed upon by the health facility staff.

\section{Data Analyses}

Data from the fully completed questionnaires were then entered into an Excel spreadsheet database and then imported into SPSS (the Statistical Package for the 


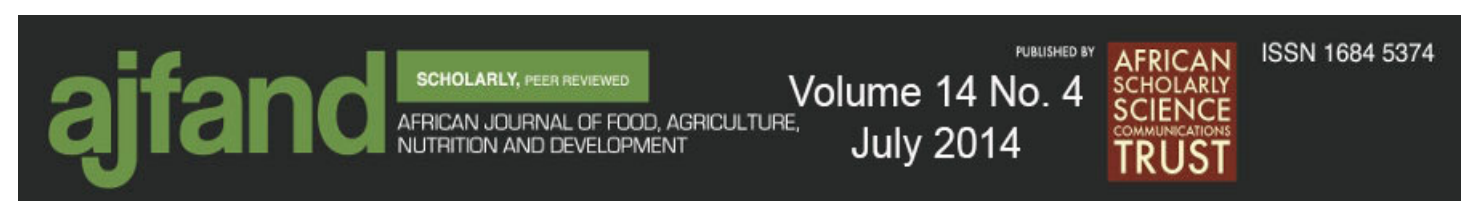

Social Sciences). Data was subsequently analysed using SPSS version 19.0 (SPSS for Windows, SPSS Inc., Chicago, IL, USA). Chi-square cross-tabulations were conducted for the different variables and $p$-value $<0.005$ was considered significant. Descriptive statistics presented as frequencies were also generated for exclusive breastfeeding rates, initiation of complementary feeding, reasons for early introduction of solids and complementary food types.

\section{RESULTS}

\section{Sample Characteristics}

The majority of the infants (39\%) were over 6 months of age while a majority of the mothers (34\%) were aged 21-25 years and 30\% aged 15-20 years. An estimated 34\% of the mothers never had any other children apart from the infant involved in the study. Mother's age was significant to the number of children born by the mother (excluding the one involved in the study) with a p-value of 0.001. Close to $60 \%$ of all infants had suffered flu in the first year of life, $48 \%$ cough, 38\% malaria. It was also noted however, that most of the infants had suffered more than a single illness in the first year of life (Table 1). Generally, the majority of the mothers were young mothers with the youngest being 15 years of age.

\section{Breastfeeding and breast milk substitutes}

Approximately 64\% of all the babies returned home from delivery centres where they were initiated onto breast milk. Overall, 94\% of all the infants were not exclusively breastfed for 6 months. Moreover, $1 \%(n=1)$ of the infants below 6 months and $6.0 \%(n=12)$ of infants above 6 months were still exclusively breastfeeding at the time of the survey. In fact, $52 \%$ of the 87 mothers, who introduced cow milk as first complementary food, gave cow milk before one month old. Moreover, $40 \%$ of all the infants were fed cow milk in the first 6 months of life ( $77 \%$ of whom were fed unprocessed cow milk). An additional $12 \%$ of all the infants were fed formula milk in the first 6 months of life.

\section{Introduction to solids}

About $5.0 \%$ of the mothers planned to introduce first solid foods to the infants at $0-1$ months, $22 \%$ at $2-3$ months and $5.0 \%$ at $4-5$ months. Moreover, $30 \%$ of all the mothers planned to give mostly beans as the first solid food at $0-1$ month, $62 \%$ soy porridge at $2-3$ months and $60 \%$ beans at $4-5$ months. Beans were the most planned first solid food for the infants. As many as $22 \%$ of the mothers actually introduced solid foods before one month, $14 \%$ at 1-3 months and 6\% between 4-6 months (Table 2). Mushrooms and ghee (36\% and 31\%) were the most frequently introduced first solids at less than 1 month and at 4-6 months respectively while soy porridge (38\%) was the most frequently introduced first solid food at 1-3 months. Mother's age was not significant in determining the age for the introduction of first solid foods fed to the infants $(p=0.095)$. Insufficient breast milk (69\%) was the main reason given for early introduction of solid foods, $10 \%$ work and 4\% was due to advice (Table 3). Only 53\% of all mothers reported 


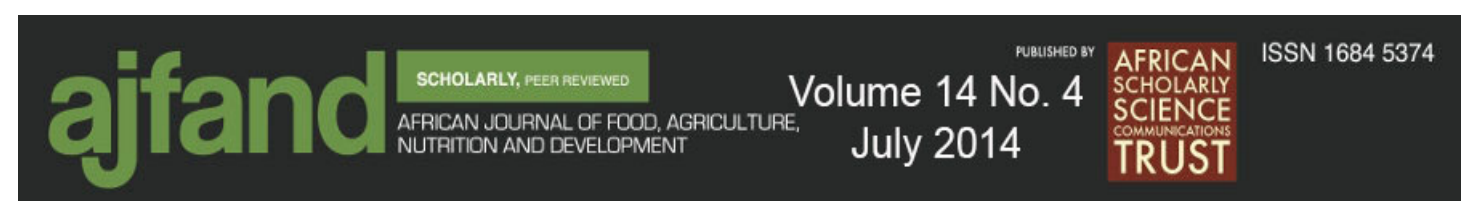

receiving information on starting to feed infants solid foods. Of these sources, $48 \%$ were from health practitioners, $23 \%$ family members and $13 \%$ public health nutritionists (Table 4). Family members were a significant source of information on feeding solids $(p=0.001)$. Similarly, $99 \%$ of all mothers agreed that more information regarding the introduction of infant solid foods should be made available with $39 \%$ of those preferring it through clinical nurses and $21 \%$ health practitioners.

\section{Red meat and iron}

Approximately $29 \%$ of all the mothers avoided giving beef to their infants before 12 months. The main reason for delaying introduction of beef and other meat sources was texture (Table 5). Cost was another concern for the late introduction of sausages constituting 24\% of all the recorded reasons and 13\% for pork (Table 5). Not only did mothers introduce red meat late in the weaning diet but also they had planned that it would be late with $39 \%$ of mothers planning to introduce red meat into the children's diet at 10-12 months and 23\% when the infants were over 12 months of age (Table 6). The main reasons for the late introduction of red meat were choking and texture accounting for 58\% of the reasons given (Table 7). Only $19 \%$ of all the mothers were able to provide an example of an iron-rich food source. Furthermore, just $6.0 \%$ gave red meat and $3.0 \%$ red vegetables as examples (data not shown).

\section{DISCUSSION}

\section{Breastfeeding and breast milk substitutes}

The prevalence of exclusive breastfeeding was considerably lower than recommended with as many as $94 \%$ of infants in this study not being exclusively breastfed for the recommended 6 months duration. The UDHS (2006) provides data on infant and young child feeding trends based on a 24-hour recall. In the 24 hours prior to the survey, $57 \%$ of infants aged $0-5$ months were exclusively breastfed in 1995. The exclusive breastfeeding rate increased to 63\% in 2000/01 and then dropped to $60 \%$ in 2006 [10].The findings of this study are in agreement with the review based on demographic and health survey data where breastfeeding patterns and exposure to suboptimal breastfeeding among children in developing countries were low with exclusive breastfeeding rate of $41 \%$ in eastern Africa among infants up to 6 months [14].

The majority of the mothers (34\%) were young aged 21-25 years and 30\% aged between 15-20 years. Mother's age was significant to the number of children born by the mother $(p=0.001)$. The young mothers pose questions over control on what the infants eat, help and maintenance of the healthful early infant eating habits. Younger mothers wean earlier than their older counterparts. Young mothers are often faced with multiple barriers and challenges such as being unprepared for potential responsibility, lack experience, and depend on guardians for financial support [15]. In this study, 52\% of the 87 mothers, who introduced cow milk as first food, gave cow milk before one month and $12 \%$ of all the mothers gave 


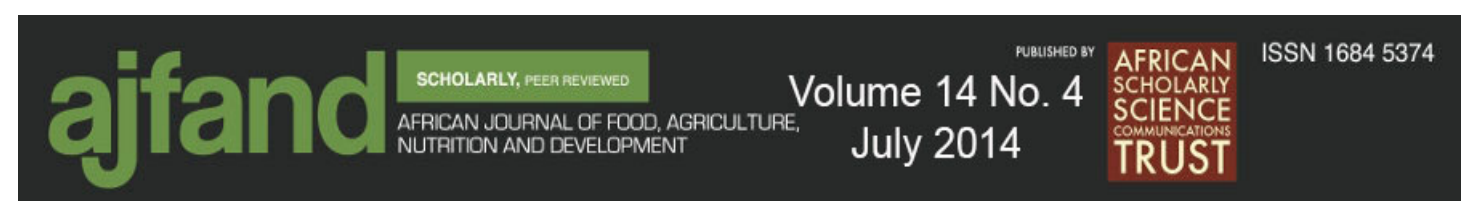

formula milk in the first 6months of life. Additionally, $6.0 \%$ of all the infants above 6 months were still exclusively breastfeeding at the time of the study without introduction of complementary foods. Tessema and Hailu [2] found that it was a common practice to introduce complementary foods earlier with up to half the population in some communities withholding complementary foods for 9 months and more. This practice however, is associated with increased risk of nutritional marasmus. The findings of this study (in which supplemental and formula milk were introduced earlier than 6 months) are in agreement with the studies in eastern Kenya where by age 3 months, 90\% of infants were already receiving supplemental feedings of cow milk and maize or millet gruels [3].

Forty percent of all the infants in this study were fed cow milk in the first 6 months of life with $77 \%$ receiving unprocessed cow milk. The high calcium and casein fractions in cow milk form complexes with iron making it unavailable for the infant body's digestion and absorption. Moreover, consuming cow milk during the first year of life and delaying the introduction of solid foods after 6 months of age were found to be important predictors of iron deficiency anaemia [16].

Anaemia is a major public health problem in developing countries, particularly for pregnant women and young children [17]. Approximately $47 \%$ of children younger than 5 years of age in developing countries are anaemic. In the eastern Uganda, $40 \%$ of children below 5 years suffer from iron deficiency anaemia [7]. Although iron deficiency anaemia accounts for a large proportion of anaemia, the anaemia of chronic inflammation (which also includes the anaemia from infections such as malaria and hook worms) may account for a substantial proportion of anaemia among children [7]. In this study, 38\% of the infants suffered malaria and 19\% diarrhoea in their first year of life. The high prevalence of anaemia in Uganda may be aggravated by a high prevalence of malaria, hookworm infection, schistosomiasis and sickle cell anaemia. It may also be accounted for by the practices observed in this study of early introduction of cow milk (43\%) and the late introduction of iron rich sources especially red meat (31\%).

The intake of formula milk was just $12 \%$ in this study. This intake is considerably lower compared to the cow milk intake of $40 \%$. This is attributed to the high cost of infant formula which is impractical yet the cost of cow milk (particularly the unprocessed) is lower. From a study conducted in Malawi, liquid formula was found to be impractical due to the weight and shipping costs. The cost of dry formula is USD13.60 per month for an infant aged 7-12 months, which far exceeds the per capita health budget in most sub-Saharan countries [18].

\section{Introduction to solids}

The World Health Organization emphasizes that complementary feeding should be timely, safe, adequate in terms of variety of foods, frequency, amounts and consistency and foods given in an appropriate way [1]. Moreover, 5.0\% of the mothers in the study planned to introduce solid foods to the infants at an age of 0 - 


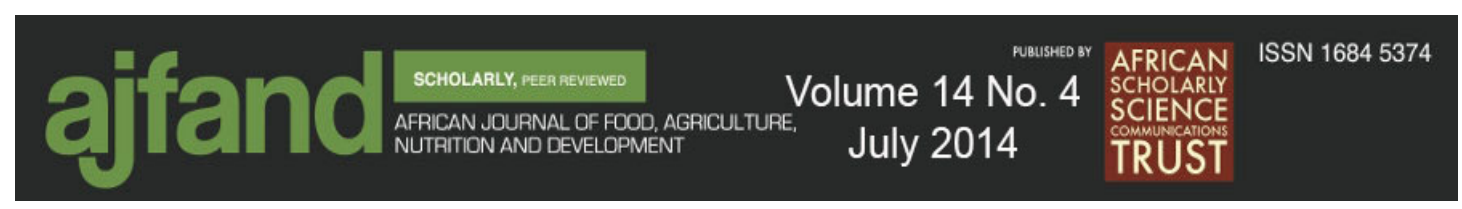

1month, $22 \%$ at $2-3$ months and $5.0 \%$ at $4-5$ months. Concurring with their intentions $22 \%$ of the mothers actually introduced solid foods before 1 month, $14 \%$ at $1-3$ months and $6.4 \%$ at $4-6$ months. Mother's age was not significant in determining the age for the introduction of first solid foods fed to the infants with p-value of 0.095 . The early introduction of solids to the infants in this survey thus mirrored the early planned introduction of solids.

Mushrooms and ghee (36\%) were the most common first solid foods introduced to the infant before 1 month while soy porridge (38\%) was the most commonly introduced solid at 1-3 months. Foods from plant sources such as soy supply inadequate amounts of nutrients due to presence of anti-nutritional factors (phytic acid and oxalic acid) that bind the micronutrients and make them unavailable in the diet. Plant food diets also have poor organoleptic qualities that further diminish appetites already suppressed by physiological nutrient deficiencies [19]. The solid food feeding pattern in this study is in agreement with the findings of Hautvast et al. [20] in which cereals, roots and tubers in infant foods accounted for more than three-quarters of energy intake and in some cases smaller proportions of protein and micronutrient intakes. This is one of the explanations why micronutrient deficiencies are still a public health problem in sub-Saharan Africa.

Approximately 29\% of all the mothers avoided giving beef to the infants before 12 months with choking and texture constituting 58\% of all the concerns. Mothers need to be educated in the skills needed to prepare weaning foods in order to eliminate the said concerns. In addition, such education would facilitate the timely introduction of iron-rich food sources into the infant's weaning diet. Cost was also a major concern for the late introduction of more specialised products as sausages that are enriched with bioavailable iron. Poverty is the reason most often given for the minimal amounts or absence of animal food sources in the diet. Nonetheless, the demand for animal foods is growing in the developing world. Meat is mostly held in high regard and valued for its prestige, ceremonial and "health value" [21].

\section{Reasons for giving first solid foods}

Insufficient breast milk (69\%) was the main recorded reason for introducing first solid foods. However, the perceived 'insufficient milk' may not reflect the true reasons for introduction of solid foods but may be given by mothers as a socially acceptable reason when mothers want to stop breastfeeding. Moreover, a study in Beijing showed that before the introduction of the Baby-Friendly Hospital Initiative in 1995, 33\% of the mothers claimed they terminated breastfeeding because of disliking or feeling uncomfortable with breastfeeding. Only $8.5 \%$ mothers ceased breastfeeding because of perceived "insufficient milk" [22]. After the introduction of Baby-Friendly Hospital Initiative, mothers were more aware of the importance of breastfeeding and less than $14 \%$ mothers gave "dislike or feel uncomfortable with breastfeeding" as the reason for stopping breastfeeding. The reason that 'insufficient milk' increased to more than 35\% while other reasons 


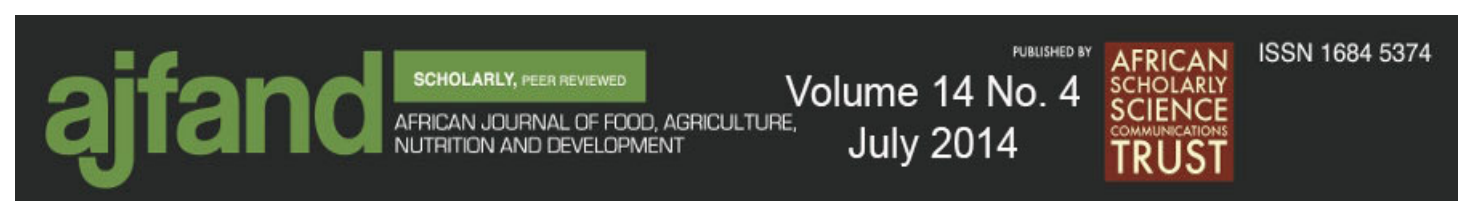

changed little may be due to the fact that the mothers changed the excuse of 'dislike or feeling uncomfortable with breastfeeding' to 'insufficient milk' for not breastfeeding infants [22].

Return to paid work was another factor recorded for the introduction of solid foods constituting $9.8 \%$ of all the reasons given by all the mothers who introduced first solid foods. In Uganda not much information is available with respect to paid employment and cessation of breastfeeding and/or the introduction of solid foods. However, a study in Taiwan identified return to work as a major reason given by $13 \%$ of the mothers who never breastfed. The results of the Taiwan study indicated that an early return to work is a significant factor in the decision whether or not to breastfeed and thus a friendlier work environment with regard to breastfeeding might encourage the practice [23].

Advice was also another reason given by mothers that prompted the early introduction of solid foods. Approximately 53\% $(n=107)$ of the mothers admitted receiving information on starting to feed infants solid foods. Moreover, $48 \%$ of those were advised by the health practitioners and $13 \%$ by the public health nutritionists. Similarly, $99 \%$ of all mothers agreed that more information in regard to starting to feed solid foods to infants should be made available with $39 \%$ of those preferring it came from clinical nurses and 21\% health practitioners. Professionals often differ in the feeding advice that they provide to parents. Public health recommendations sometimes differ from those provided by clinical practitioners in the advice they give to parents. For example, most public health organizations recommend breastfeeding for at least a year yet the WHO guidelines suggest an even longer period, whereas individual practitioners may provide different advice to mothers for managing their infants [16]. Individual professionals and working groups within professional societies also sometimes differ in their views on appropriate advice for mothers on such topics as the timing of introduction of complementary feedings. It is important therefore that the messages about weaning in terms of appropriate timing (not too early or late) and also iron-rich foods be consistent among health professionals.

Almost 23\% of those mothers who received information on starting to feed solid foods recorded advice from family members. Family members were a significant source of information on feeding solids with $p=0.001$. It is common practice in Uganda especially for the grandmothers to provide information on introduction of first solid foods. Similarly, earlier studies in Malawi indicate that there were four primary foods/liquids introduced to infants prior to 6 months (presented in order of introduction): mzuwula (a type of herbal infusion), water, dawale (another herbal infusion) and porridge [24]. In $78 \%$ of the 86 cases where mzuwula was introduced, the paternal grandmother made the decision while in $30 \%$ of the 173 cases where water or dawale water was introduced, the paternal grandmother decided, and the grandmother decided to give dawale in $56 \%$ of the 41 cases where dawale alone was introduced. Grandmothers also decided to introduce porridge in $21 \%$ of the 230 cases where it was introduced prior to 6 months [24]. 


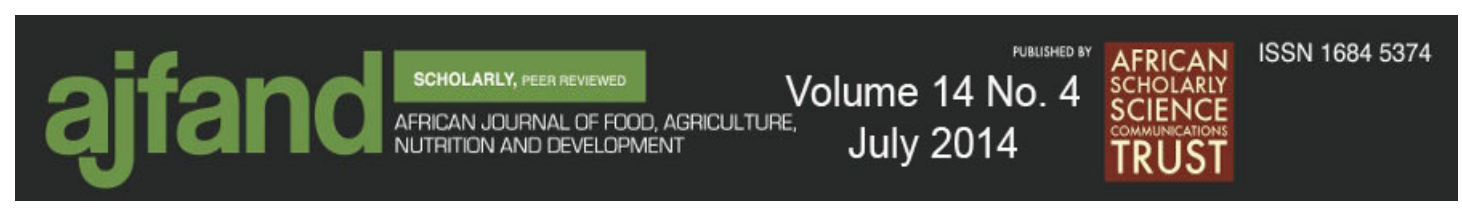

'The Grandmother Project', spearheaded a transformative, participatory health education approach to integrating grandmothers in nutrition education [25].

\section{Red meat and iron}

The prevalence of iron deficiency anaemia is estimated at approximately $42 \%$ in developing countries and $17 \%$ in developed countries [26]. Uganda has no iron supplementation policy for the children below 5 years and infants entirely depend on iron food sources (red meat, fish, fowl and red vegetables). The majority (39\%) of all the mothers in this study planned to introduce red meat at 10-12 months and 23\% after 12 months. During the second 6 months of life in infants fed breast milk, greater than $90 \%$ of iron requirements must be met by complementary feeding to decrease the risk of developing iron deficiency or even iron deficiency anaemia, which is thought to be associated with adverse outcomes of neurodevelopment [27].

Recent estimates indicate that 23-33\% of children from developing countries below 4 years have iron deficiency anaemia [28]. In eastern Uganda, 40\% of children below 5years suffer from iron deficiency anaemia [6]. However, only $19 \%$ of all the mothers in this study were able to record an example of an iron food source with $18 \%$ recording red meat and $13 \%$ red vegetables. Animal source foods compared to plant source foods, are energy-dense and an excellent source of high-quality and readily digestible protein [29]. Red meat has a high content and bioavailability of micronutrients; that is, there is a high level of absorption and utilization by the body because of the presence of heme-protein found only in meat, fish and fowl. The fact that red meat was introduced late in the children diets and that fewer mothers were able to identify an iron food source hence explains the high prevalence of anaemia and iron deficiency anaemia in Uganda.

\section{CONCLUSION AND RECOMMENDATIONS}

The prevalence of exclusive breastfeeding in this study is extremely low. Cow milk and solid foods were introduced earlier than recommended. Family members were an important source of information on feeding infants solid foods. The low breastfeeding rates, early introduction of cow milk and solid foods are thus responsible for the high infant infection rates recorded in the first year of life. Improved knowledge among mothers about infant feeding is needed and this should come from health professionals providing consistent information. Furthermore, a nutritional education intervention, promoting exclusive breastfeeding and the health benefits associated with it, highlighting the health and food safety risks associated with the early introduction of and solid foods (especially iron-rich sources) into the infant diets could help reduce the high levels of malnutrition, infant infections and mortality in Uganda. 


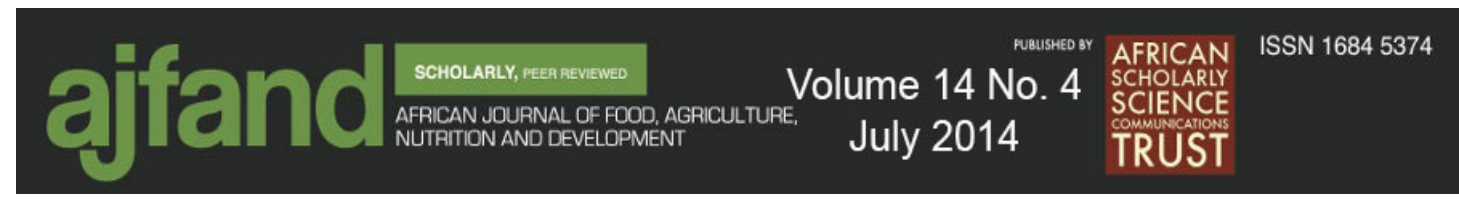

Table 1: Sample characteristics of infants and mothers

\begin{tabular}{|c|c|c|}
\hline Infants age & $\begin{array}{c}\text { Number } \\
(n=204)\end{array}$ & Percentage (\%) \\
\hline 1 month & 15 & 7.4 \\
\hline 2-3 months & 46 & 22.5 \\
\hline 4-6 months & 63 & 30.9 \\
\hline$>6$ months & 80 & 39.2 \\
\hline \multicolumn{3}{|l|}{ Mothers age } \\
\hline $15-20$ years & 62 & 30.4 \\
\hline 21-25 years & 69 & 33.8 \\
\hline 26-30 years & 44 & 21.6 \\
\hline 31-35 years & 22 & 10.8 \\
\hline$>35$ years & 7 & 3.4 \\
\hline \multicolumn{3}{|c|}{$\begin{array}{l}\text { Number of children } \\
\text { excluding infant in the } \\
\text { study }\end{array}$} \\
\hline None & 70 & 34.3 \\
\hline$\geq 1$ child & 134 & 65.7 \\
\hline \multicolumn{3}{|c|}{$\begin{array}{l}\text { Infant illness in first year } \\
\text { of life }\end{array}$} \\
\hline Flu & 122 & 59.8 \\
\hline Cough & 97 & 47.6 \\
\hline Malaria & 78 & 38.2 \\
\hline Diarrhoea & 39 & 19.1 \\
\hline Pneumonia & 3 & 1.5 \\
\hline
\end{tabular}




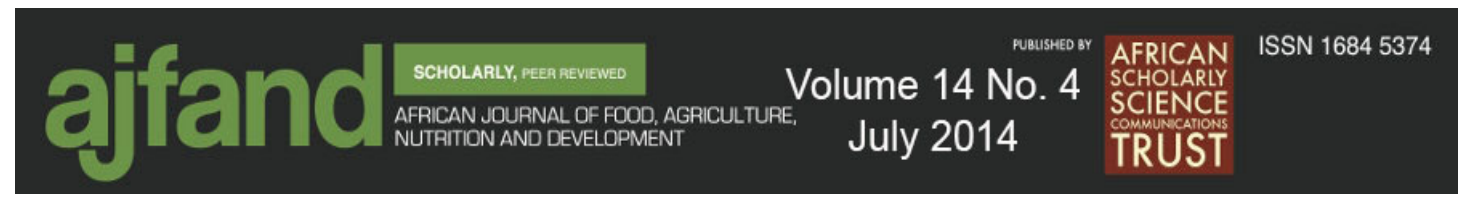

Table 2: The first introduction of solids

\begin{tabular}{|c|c|c|c|c|c|c|c|c|}
\hline \multirow[t]{2}{*}{ Food } & \multicolumn{2}{|c|}{$<1$ month } & \multicolumn{2}{|c|}{ 1-3 months } & \multicolumn{2}{|c|}{ 4-6 months } & \multicolumn{2}{|c|}{ >6months } \\
\hline & $n=44$ & $\%$ & $n=29$ & $\%$ & $n=13$ & $\%$ & $n=6$ & $\%$ \\
\hline Mushroom \& Ghee & 16 & 36.4 & 4 & 13.8 & 4 & 30.8 & - & - \\
\hline Soy porridge & 8 & 18.2 & 11 & 37.9 & 2 & 15.4 & 1 & 16.7 \\
\hline Corn porridge & 7 & 15.9 & 3 & 10.3 & 3 & 23.0 & 2 & 33.3 \\
\hline Fish & 5 & 11.4 & 4 & 13.8 & 1 & 7.7 & 2 & 33.3 \\
\hline Eggs & 3 & 6.8 & 6 & 20.7 & 2 & 15.4 & - & - \\
\hline Glucose & 3 & 6.8 & - & - & - & - & - & - \\
\hline Beans & 2 & 4.5 & 1 & 3.5 & 1 & 7.7 & 1 & 16.7 \\
\hline Total & 44 & 100 & 29 & 100 & 13 & 100 & 6 & 100 \\
\hline
\end{tabular}

Table 3: Reasons for giving first solid foods among women who have already introduced solids

\begin{tabular}{lcc}
\hline Reason & Number $(\boldsymbol{n}=\mathbf{9 2})$ & Percentage (\%) \\
\hline $\begin{array}{l}\text { Insufficient } \\
\text { breast milk }\end{array}$ & 63 & 68.5 \\
Work & 9 & \\
Disease & 5 & 9.8 \\
Advice & 4 & 5.4 \\
Minerals & 5 & 4.4 \\
Baby & 2 & 5.4 \\
weaning & & 2.1 \\
Family planning & 1 & 1.1 \\
Medical & 1 & 1.1 \\
\hline operation & & \\
\hline Child training & 2 & 2.1 \\
\hline Total & $\mathbf{9 2}$ & $\mathbf{1 0 0}$ \\
\hline
\end{tabular}




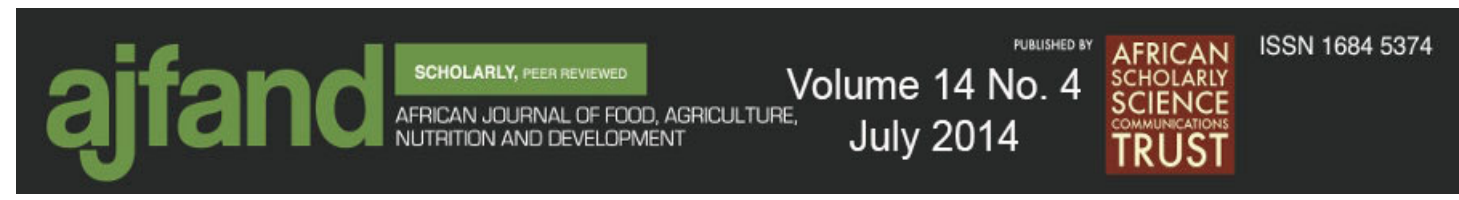

Table 4: Sources of information on starting to feed solids among mothers who received such information

\begin{tabular}{lrc}
\hline $\begin{array}{l}\text { Source of } \\
\text { information }\end{array}$ & $\begin{array}{r}\text { Number } \\
(\boldsymbol{n = 1 0 7 )}\end{array}$ & Percentage (\%) \\
\hline Health & 51 & 47.7 \\
practitioner & 25 & 23.4 \\
Family & 14 & 13.1 \\
Public health & & \\
nutritionist & 7 & 6.5 \\
Friends & 6 & 5.6 \\
Adverts & 2 & 1.9 \\
School & 1 & 0.9 \\
Internet & 1 & 0.9 \\
Civic education & $\mathbf{1 0 7}$ & $\mathbf{1 0 0}$ \\
\hline Total & & \\
\hline
\end{tabular}




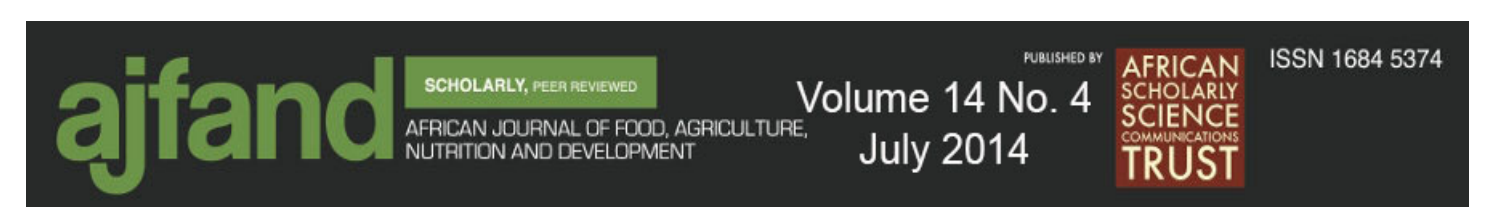

Table 5: Reasons for not giving some solids before baby is $\mathbf{1 2}$ months

\begin{tabular}{|c|c|c|c|c|c|c|c|c|c|c|c|c|c|c|c|}
\hline \multirow[t]{2}{*}{ Reason } & \multicolumn{2}{|c|}{ Beef } & \multicolumn{2}{|c|}{ Liver } & \multicolumn{2}{|c|}{ Sausage } & \multicolumn{2}{|c|}{ Pork } & \multicolumn{2}{|c|}{ Beans } & \multicolumn{2}{|c|}{ Corn porridge } & \multicolumn{3}{|c|}{ Soy porridge } \\
\hline & $n=59$ & $\%$ & $n=18$ & $\%$ & $n=50$ & $\%$ & $n=64$ & $\%$ & $n=3$ & $\%$ & $n=6$ & $\%$ & $n=4$ & & 100 \\
\hline Dietary preference & 3 & 5.1 & - & - & 10 & 20.0 & 13 & 20.3 & 1 & 33.3 & 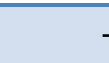 & - & & - & - \\
\hline Worms & 2 & 3.4 & - & - & - & - & - & - & - & - & . & - & & - & - \\
\hline Allergy & 2 & 3.4 & - & - & - & - & - & - & - & - & 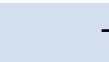 & - & & - & - \\
\hline Dental development & 15 & 25.4 & 2 & 11.1 & 4 & 8.0 & 3 & 4.6 & - & - & - & - & & - & - \\
\hline Cost & 8 & 13.6 & 1 & 5.5 & 12 & 24.0 & 8 & 12.5 & - & - & 2 & 33.3 & & 1 & 25 \\
\hline Disease & 6 & 10.2 & 3 & 16.7 & 2 & 4.0 & 8 & 12.5 & - & - & - & - & & - & - \\
\hline Choking & 12 & 20.3 & - & - & - & - & 1 & 1.6 & - & - & 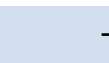 & - & & - & - \\
\hline Texture & 11 & 18.6 & 5 & 27.8 & 10 & 20.0 & 10 & 15.6 & - & - & - & - & & - & - \\
\hline Religious taboo & - & - & - & - & 2 & 4.0 & 20 & 31.3 & - & - & - & - & & - & - \\
\hline Composition & - & - & - & - & 10 & 20.0 & - & - & - & - & - & - & & - & - \\
\hline Cultural taboo & - & - & 2 & 11.1 & - & - & - & & - & - & 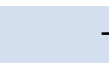 & - & & - & - \\
\hline Availability & - & - & 5 & 27.8 & - & - & - & - & - & - & 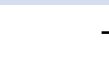 & - & & - & - \\
\hline Preparation & - & - & - & - & - & - & 1 & 1.6 & - & - & - & - & & - & - \\
\hline Flatulence & - & - & - & - & - & - & - & - & 2 & 66.7 & - & - & & - & - \\
\hline Growth inhibitors & - & - & - & - & - & - & - & - & - & - & 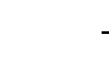 & - & & 3 & 75 \\
\hline Diarrhoea & - & - & - & - & - & - & - & - & - & - & 4 & 66.7 & & - & - \\
\hline Total & 59 & 100 & 18 & 100 & 50 & 100 & 64 & 100 & 3 & 100 & 6 & 100 & & 4 & 100 \\
\hline
\end{tabular}


Table 6: Planned introduction of red meat

\begin{tabular}{lrc}
\hline Months & $\begin{array}{r}\text { Number } \\
(\boldsymbol{n = 2 0 4 )}\end{array}$ & Percentage (\%) \\
\hline 1-3 months & - & - \\
4-6 months & 33 & 16.2 \\
7-9 months & 44 & 21.6 \\
10-12 months & 80 & 39.2 \\
>12 months & 47 & 23.0 \\
Total & $\mathbf{2 0 4}$ & $\mathbf{1 0 0}$ \\
\hline
\end{tabular}

Table 7: Main reasons for the late introduction of red meat

\begin{tabular}{lrr}
\hline Suggestion & Number $(\boldsymbol{n}=\mathbf{2 0 0})$ & Percentage (\%) \\
\hline Cost & 25 & 12.5 \\
\hline Choking & 67 & 33.5 \\
\hline Texture & 49 & 24.5 \\
\hline Preparation & 32 & 16.0 \\
\hline Good food & 10 & 5.0 \\
\hline Needs & 12 & 6.0 \\
Availability & 1 & 0.5 \\
\hline Disease & 2 & 1.0 \\
Allergy & 2 & 1.0 \\
\hline Total & $\mathbf{2 0 0}$ & $\mathbf{1 0 0}$ \\
\hline
\end{tabular}




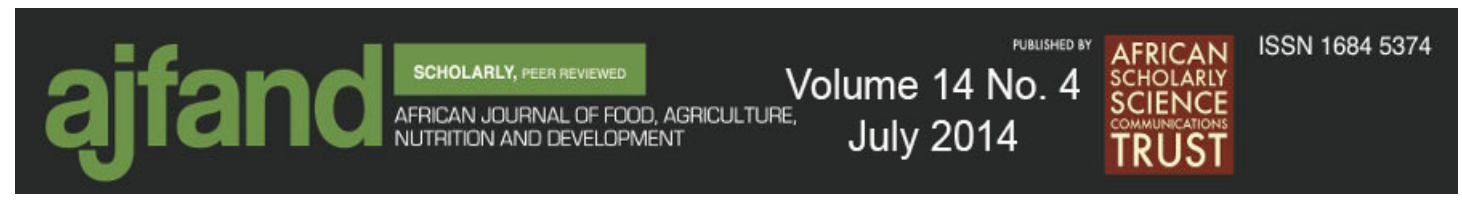

\section{REFERENCES}

1. WHO/UNICEF. Global strategy for infant and young child feeding. WHO Geneva. 2003:5-10.

2. Tessema T and A Hailu Childhood feeding practice in North Ethiopia. East. Afr. Med. J. 1997; 74: 92-95.

3. Allen LH The Nutrition Collaborative Research Support Program (CRSP): what is marginal malnutrition, and does it affect human function? Nutr. Rev. 1993; 51: 255-267.

4. World Bank. Repositioning nutrition as central to development: A strategy for large scale action. The International Bank for Reconstruction and Development Washington DC, USA, 2006.

5. Shrimpton R, Victora CG, Mercedes de Onis, Lima RC, Blössner M and G Clugston Worldwide Timing of Growth Faltering: Implications for Nutritional Interventions. Pediatr. 2001; 107: 75.

6. Uganda Demographic and Health Survey Ministry of Finance, Economic Development and Planning (1988-1989). Statistics Department 1995.

7. Bakaki PM Childhood anaemia in rural Uganda community: Kiyeyi target area Makerere University, Uganda. Dissertation 1995.

8. Kawuma $\mathbf{M}$ and $\mathbf{L}$ Sserunjogi Kamuli blindness and vitamin A demography survey. Unpublished data 1991.

9. Watkins K Human Development report: United Nations Development Programme (UNDP). New York, USA 2005.

10. Uganda Demographic and Health Survey Uganda Bureau of Statistics Entebbe (UBOS) and ORC Macro Calverton, Maryland, USA 2006.

11. Wamani H, Tylleskar T, Astrom AN, Tumwine JK and S Peterson Mothers' education but not fathers' education: household assets or land ownership is the best predictor of child health inequalities in rural Uganda. Int. J. Equity. Health. 2004; 3: 9.

12. Uganda Bureau of Statistics. Uganda Demographic Health Survey 20002001. ORC Macro Inc, Kampala, Uganda 2001.

13. Uganda Bureau of Statistics. Wakiso district profile, current situation and baseline analysis projections 2010. Uganda Bureau of Statistics, Kampala, Uganda 2010. 


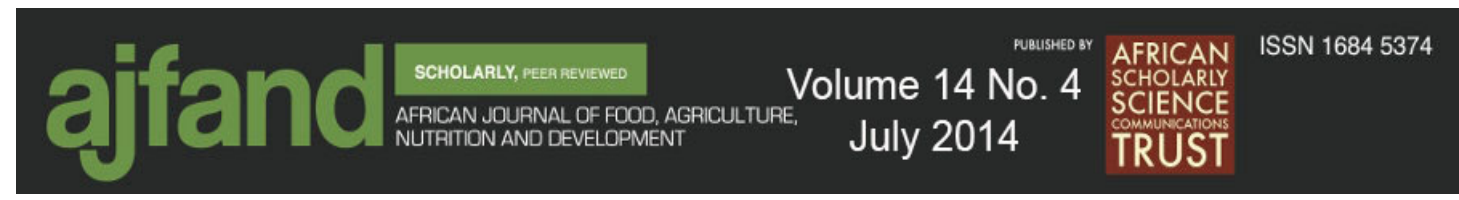

14. Lauer JA, Betran AP, Victora CG, De Onis $M$ and AJ Barros Breastfeeding patterns and exposure to suboptimal breastfeeding among children in developing countries: review and analysis of nationally representative surveys. BMC. Med. 2004; 2: 26.

15. Bentley M, Gavin L, Black MM and L Teti Infant feeding practices of low-income African-American adolescent mothers: An ecological, multigenerational perspective. Soc. Sci. Med. 1999; 49: 1085-1100.

16. DeWalt KM Nutritional strategies and agricultural change in a Mexican community: Maternal weight loss patterns during prolonged lactation. Am. J. Clin. Nutr. 1983; 58: 162-166.

17. WHO. Turning the Tide of Malnutrition: Responding to the Challenge of the $21^{\text {st }}$ Century. (WHO/NHD/00.7) Geneva, Switzerland 2000. Available at: http://www.who.int/mip2001/files/2232/NHDbrochure.pdf, Accessed July 5, 2009

18. Maclean CC and JS Stringer Potential cost-effectiveness of maternal and infant antiretroviral interventions to prevent mother-to-child transmission during breast-feeding. J. Acquir. Immune. Defic. Syndr. 2005; 38(5), 570577.

19. Golden MHN The nature of nutritional deficiency in relation to growth failure and poverty. Acta. Paediatr. Scand. 1991; 374: 95-110.

20. Hautvast JLA, van den Heijden LJM, Luneta AK, van Staveren WA, Tolboom JJM and SM van Gastel Food consumption of young stunted and non-stunted children in rural Zambia. Eur. J. Clin. Nutr. 1999; 53: 50 59.

21. Neumanna $C B$, Diane $M$, Harrisa $B$, Lisa $M$ and $B$ Rogersa Contribution of animal source foods in improving diet quality and function in children in the developing world. Center for Human Nutrition, Los Angeles. 2001: 1-28.

22. Liao J Breastfeeding and associated factors. Chinese. J. Child. Health. Care. 2000; 8 (11): 1349-1351.

23. Arora S, Mcjunkin C, Wehrer $\mathbf{J}$ and $\mathbf{P}$ Kuhn Major factors influencing breastfeeding rates: Mother's perception of father's attitude and milk supply. Pediatr. 2000; 106 (5): 67-71.

24. Bezner-Kerr R, Berti $\mathbf{P}$ and $\mathbf{M}$ Chirwa Breastfeeding and mixed feeding practices in Malawi (timing, reasons, decision makers, and child health consequences). Food. Nutr. Bull. 2007; 28(1): 90-99. 


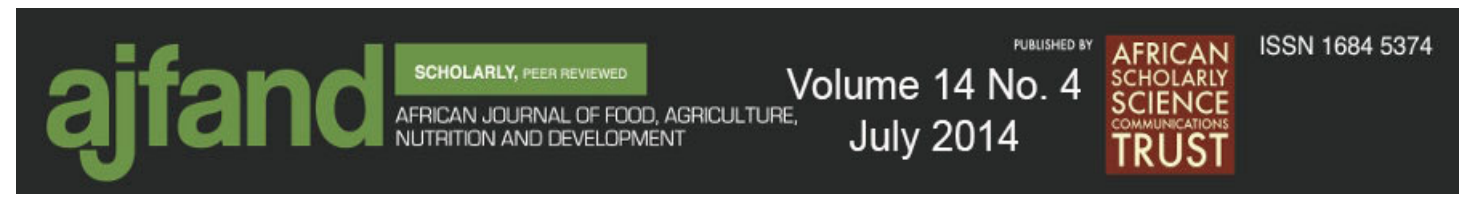

25. Aubel $\mathbf{J}$ Generic steps in the grandmother-inclusive methodology: The Grandmother Project 2004.

26. McLean E, Cogswell M, Egli I, Wojdyla D and B De Benoist Worldwide prevalence of anaemia: WHO vitamin and mineral nutrition information system 1993-2005. Pub. Health. Nutr. 2009; 12(4): 444-54.

27. Domellöf $\mathbf{M}$ Iron requirements, absorption and metabolism in infancy and Childhood. Curr. Opin. Clin. Nutr. Metab. Care. 2007; 10(3): 329-35.

28. Stoltzfus $\mathbf{R}$, Mullany $\mathbf{L}$ and $\mathbf{R}$ Black Iron deficiency anemia: Comparative quantification of health risks, global and regional burden of disease attributable to selected major risk factors. WHO. 2005: 163-209.

29. Bender A Meat and meat products in human nutrition in developing countries. Food and Nutrition Paper \#53, Food Policy and Nutrition Division of FAO 1992; 2: 1-88. 